\title{
Development of a Zebrafish Model for Rapid Drug Screening against Alzheimer's Disease
}

\author{
Wenhai Huang ${ }^{1}$, Chuansheng $\mathrm{Li}^{1}$, Zhengrong Shen ${ }^{1}$, Xiaoyu Zhu ${ }^{2}$, Bo Xia ${ }^{2}$ and Chunqi $\mathrm{Li}^{2}$ \\ 1. Institute of Materia Medica, Zhejiang Academy of Medical Sciences, Hangzhou 310013, Zhejiang Province, China \\ 2. Hunter Biotechnology Inc., Transfarland, Hangzhou 310013, Zhejiang Province, China
}

\begin{abstract}
Alzheimer's disease, the leading cause of dementia in the elderly, is a complex neurodegenerative disorder which leads to a progressive decline in cognitive functions. A rapid screening model is highly demanded for identification and evaluation of novel anti-Alzheimer's disease drugs from a large numbers of compounds. Until now, numerous studies utilized zebrafish model for drug discovery. Since aluminum can induce a similar biological activity in zebrafish as in Alzheimer patients, in this study, we developed a novel animal model using 3 to 5 day post-fertilization larval zebrafish by optimizing the doses and duration of aluminum chloride exposure. Six anti-Alzheimer's disease drugs with a variety of mechanisms were tested to validate the newly developed zebrafish model. Importantly, Rivastigmine, ThT, Flurbiprofen and AM-117 could increase the value of Dyskinesia Recovery Rate by 53.4-64\%, 169.4-200\%, 54.5-96\% and 70.9-121\%, respectively. Rivastigmine, Memantine, ThT, Flurbiprofen, Rosiglitazone and AM-117 improved the value of Response Efficiency by 86.6-175.1\%, 28.2-66.6\%, 127.2-236.5\%, 118.3-323.7\%, 26.6-140.8\% and $70.2-161.4 \%$, respectively. Our results suggest that the zebrafish model developed in this study could be a useful tool for high throughput screening of potential novel anti-Alzheimer's disease leading compounds targeting acetylcholinesterase, $\mathrm{N}$-methyl-D-aspartic acid receptor, $\gamma$-secretase, peroxisome proliferator-activated receptor- $\gamma$ and amyloid- $\beta$.
\end{abstract}

Key words: Alzheimer's disease, 3-5dpf Larvae, screening platform, zebrafish model.

\section{Introduction}

$\mathrm{AD}$ (Alzheimer's disease), the leading cause of dementia in the elderly, is a complex neurodegenerative disorder which often leads to a progressive decline in cognitive functions $[1,2]$. Many in vitro and in vivo studies demonstrated that multiple factors, such as low acetylcholine level, metal dyshomeostasis, oxidative stress and $\mathrm{A} \beta$ (amyloid- $\beta$ ) aggregation, may be involve in the development of AD [3-5]. However, the pathogenesis of $\mathrm{AD}$ still remains to be elucidated.

In order to screen the anti-AD drug, the experimental animal models that mimic $A D$ pathological processes are essential. For a long time, mice have been the dominant system for the study of

Corresponding author: Zhengrong Shen, professor, Focus on anti-AD and anti tumor drug discovery, Institute of Materia Medica, Zhejiang Academy of Medical Sciences, 182 Tianmushan Road, West Lake District, Hangzhou, Zhejiang Province, China. E-mail: shenzr@zjams.com.cn.
Alzheimer's disease [6, 7]. In recent years, zebrafish models have attracted great attention and are widely used due to its cost-efficiency. For example, Paquet et al developed a tau transgenic zebrafish model to identify the compounds that targeted tau phosphorylation [8]. Inhibition of GSK3, a potential $\mathrm{AD}$ drug target, led to the headless embryo of zebrafish, in which the phenotype was used to successfully identify several GSK3 $\beta$ inhibitors $[9,10]$. However, most of the zebrafish models of $\mathrm{AD}$ are transgenic, which is cost- and time-consuming, a new zebrafish model for rapid screening of anti-AD drugs is highly demanded.

Aluminum chloride is a standard chemical previously used to induce $\mathrm{AD}$ models in rodents $[5,11$, 12]. Given the fact that aluminum can reduce the locomotor activity in 6-8 months old of zebrafish, a similar biological phenomenon to the dyskinesia in $\mathrm{AD}$ patients [13], we sought to create a new zebrafish 
model by aluminum chloride exposure. Here in this study, we utilized 3-5 dpf (day post-fertilization) fish larvae, instead of 6-8 months zebrafish described previously as an optimum stage of zebrafish, to create an AD model in order to perform high-throughput drug screening as well as cut the cost. Three conditions $(\mathrm{AlCl} 3$ exposure concentration, $\mathrm{AlCl} 3$ exposure period and drug treatment concentration) were optimized in the model development, of which Donepezil was used as a positive control drug. Six anti-AD drugs (Table 1) marketed, or in clinical trials, with a variety of mechanisms of action were applied to validate the model. DRR (Dyskinesia Recovery Rate) and RE (Response Efficiency) to light change were used to quantify the drug efficacy. Our results demonstrated that RE could be used as a reliable and convenient measurement to evaluate all 6 anti-AD drugs; whereas DRR was effective for Rivastigmine, Thioflavine T, Flurbiprofen and AM-117, but not for Memantine and Rosiglitazone.

\section{Methods}

\subsection{Zebrafish Handling}

The wild-type zebrafish of both sexes were used in this study. Zebrafish embryos were generated by natural pairwise mating in our aquaculture facility. The fish were kept in the reverse osmosis water containing $200 \mathrm{mg} / \mathrm{L}$ sea salt (conductivity of 480-510 $\mu \mathrm{S} / \mathrm{cm}$; $\mathrm{pH}$ of $6.9-7.2$; hardness of $53.7-71.6 \mathrm{mg} / \mathrm{L}$ $\mathrm{CaCO}_{3}$ ) on a $14 / 10 \mathrm{~h}$ light/dark cycle (lights on at
8:30 a.m.) at a temperature of $28{ }^{\circ} \mathrm{C}$. After the completion of the experiment, $0.25 \mathrm{mg} / \mathrm{ml}$ tricaine methanesulfonate was used to kill the various developmental stages of zebrafish. The procedures were in accordance with EU Directive 2010/63/EU for animal experiments.

\subsection{Chemicals}

Acetylcholinesterase inhibitor DPZ (donepezil) was purchased from TRC Canada. Memantine and Aluminum chloride were purchased from Aladdin Reagent Inc. Flurbiprofen and ThT were purchased from Sigma-Aldrich Co., Ltd. Rosiglitazone was purchased from Nanjing Tianzun Zezhong Chemical Co., Ltd. AM-117 was synthesized in our laboratory.

\subsection{Zebrafish AD Model Development}

\subsubsection{Optimization of $\mathrm{AlCl}_{3}$ Exposure}

Concentration

For zebrafish, most developmental processes occur within the first day, and the endothelial BBB (blood-brain barrier) begins to function at $3 \mathrm{dpf}$ [14]. Consequently, 3dpf zebrafish were chosen as an optimal stage for the model development. The zebrafish were placed in a 6-well microplate at a density of 30 zebrafish per well and treated with $\mathrm{AlCl}_{3}$ with three various concentrations $(15,50$ and $150 \mu \mathrm{M})$ from $3 \mathrm{dpf}$ to $5 \mathrm{dpf}$ to determine the optimal exposure concentration of $\mathrm{AlCl}_{3}$. After adding $150 \mu \mathrm{M}$ of $\mathrm{AlCl}_{3}$, fish water $\mathrm{pH}$ value was reduced to 5.0.

Table 1 Anti-AD drugs used in the study.

\begin{tabular}{|l|l|l|l|}
\hline Drug & Mechanism & Target(s) & Status \\
\hline Donepezil (DPZ) & acetylcholinesterase inhibitor & acetylcholinesterase & Approved for AD \\
\hline Rivastigmine & acetylcholinesterase inhibitor & acetylcholinesterase & Approved for AD \\
\hline Memantine & $\begin{array}{l}\text { N-methyl-D-aspartic acid receptor } \\
\text { antagonist }\end{array}$ & N-methyl-D-aspartic acid receptor & Approved for AD \\
\hline Thioflavine T & A $\beta$ aggregation inhibitor & $\mathrm{A} \beta$ & Tool medicine for AD \\
\hline Flurbiprofen & $\gamma$-secretase inhibitor & $\mathrm{A} \beta$ & $\begin{array}{l}\text { Approved for nonsteroidal } \\
\text { anti-inflammatory drug } \\
\text { Phase III clinical trials for AD }\end{array}$ \\
\hline Rosiglitazone & PPAR $\gamma$ agonist & A $\beta$ & $\begin{array}{l}\text { Approved for hypoglycemic drug } \\
\text { Clinical trials for AD }\end{array}$ \\
\hline AM-117 & $\begin{array}{l}\text { acetylcholinesterase inhibitor and } \\
\text { metal chelator }\end{array}$ & acetylcholinesterase and Metal ions & Pre-clinical study \\
\hline
\end{tabular}




\subsubsection{Optimization of $\mathrm{AlCl}_{3}$ Exposure Period}

After the optimization of $\mathrm{AlCl}_{3}$ exposure concentration, $150 \mu \mathrm{M} \mathrm{AlCl}{ }_{3}$ was used to treat zebrafish with various time periods: from 2 dpf to 5 dpf, $3 \mathrm{dpf}$ to $5 \mathrm{dpf}$ and $4 \mathrm{dpf}$ to $5 \mathrm{dpf}$ respectively (30 zebrafish per group), and the optimal $\mathrm{AlCl}_{3}$ exposure period was selected.

2.3.3 Optimization of the Positive Control Drug Concentration

$\mathrm{DPZ}$, approved for $\mathrm{AD}$, was selected as the positive control drug. To optimize the concentration of drug treatment, zebrafish were co-treated with $150 \mu \mathrm{M}$ $\mathrm{AlCl}_{3}$ and $5 \mu \mathrm{M}$ or $10 \mu \mathrm{M} \mathrm{DPZ}$ from $3 \mathrm{dpf}$ to $5 \mathrm{dpf}$ (30 zebrafish per group).

\subsubsection{Model Grouping}

Zebrafish were divided into four groups: control group, vehicle group, model group and model+DPZ group, each of which contained 30 zebrafish. The control group was maintained in the reverse osmosis water. The vehicle group was treated with $0.5 \%$ DMSO (dimethyl sulfoxide). The model group was treated with $150 \mu \mathrm{M} \mathrm{AlCl}$ from 3 dpf to $5 \mathrm{dpf}$. The model + DPZ group was co-treated with $150 \mu \mathrm{M}$ $\mathrm{AlCl}_{3}$ and $10 \mu \mathrm{M} \mathrm{DPZ}$ from $3 \mathrm{dpf}$ to $5 \mathrm{dpf}$. All experiments were repeated for at least 3 times after experimental conditions were optimized.

\subsection{Assessing Anti-AD Drugs in the Zebrafish $A D$ Model}

2.4.1 Determination of NOAEL (No Observed Adverse Effect Level)

The zebrafish were treated with $150 \mu \mathrm{M} \mathrm{AlCl}_{3}$ from $3 \mathrm{dpf}$ to $5 \mathrm{dpf}$, and then treated with a testing drug at 5 various concentrations $(0.1 \mu \mathrm{g} / \mathrm{Ml}, \quad 1 \mu \mathrm{g} / \mathrm{mL}, 10$ $\mu \mathrm{g} / \mathrm{mL}, 100 \mu \mathrm{g} / \mathrm{mL}$ and $500 \mu \mathrm{g} / \mathrm{mL}$ ) from $3 \mathrm{dpf}$ to 5 dpf. Each concentration of each drug contained 30 zebrafish. The survivals were counted and the NOAEL of each drug was calculated by spss software (version 16.0).

\subsubsection{Testing drug grouping}

240 zebrafish were divided into eight groups (30*
8) for each drug. Besides the four groups mentioned in part 2.3.4, Control + Drug $C_{\text {high }}$ group, Model + Drug $\mathrm{C}_{\text {low }}$ group, Model + Drug $\mathrm{C}_{\text {moderate }}$ group and Model + Drug $\mathrm{C}_{\text {high }}$ group were added. The $\mathrm{C}_{\text {low }}, \mathrm{C}_{\text {moderate }}$ and $\mathrm{C}_{\text {high }}$ were established based on the NOAEL of each drug $\left(\mathrm{In}\right.$ most cases, $\mathrm{C}_{\text {high }}=$ NOAEL, $\mathrm{C}_{\text {moderate }}=$ $1 / 5$ NOAEL, $\mathrm{C}_{\text {low }}=1 / 25$ NOAEL). The Control + Drug $C_{\text {high }}$ group was maintained in the reverse osmosis water from $3 \mathrm{dpf}$ to $5 \mathrm{dpf}$, and treated with the high concentration of a drug. Model + DrugC $_{\text {low }}$ group, Model + DrugC $_{\text {moderate }}$ group and Model + DrugC $_{\text {high }}$ group were co-treated with $150 \mu \mathrm{M} \mathrm{AlCl}_{3}$ and a testing drug at low, moderate, high concentrations, respectively from $3 \mathrm{dpf}$ to $5 \mathrm{dpf}$.

\subsection{Experiment Procedure and Video Tracking}

$5 \mathrm{dpf}$ larvae were loaded into 48-well plates (Nest Biotech), the temperature of which was maintained at $28{ }^{\circ} \mathrm{C}$. All experiments consisted of $60 \mathrm{~min}$ containing 3 cycles of a light/dark phase (10 min light and 10min dark each). Zebrafish movement $\mathrm{D}$ (distance) and $\Delta \mathrm{S}$ (speed change) to light-dark and dark-light cycles were recorded by viewpoint behavior analyzer (Zebralab V3, ViewPoint Life Sciences Co., Ltd.) for further analysis. Zebrafish movement distance was used for DRR quantification and $\Delta \mathrm{S}$ for calculating RE.

\subsection{Data Analysis}

Via SPSS software (version 16.0), data were expressed as means \pm SEM, and analyzed by ANOVA and Dunnett's method to test for variability between each trial considering $\mathrm{P} \leq 0.05$ as a significant. DRR and $\mathrm{RE}$ are two selected parameters for assessing anti-AD drug efficiency in this model $[15,16]$. DRR was defined as $D R R(\%)=\frac{\mathrm{AS}_{\text {drug }}-\mathrm{AS}_{\text {model }}}{\mathrm{AS}_{\text {venicle }}-\mathrm{AS}_{\text {model }}} \times 100 \%$, where $\mathrm{AS}$ was defined as $A S=D / T$, where $D$ is the movement distance of zebrafish, $\mathrm{T}$ is the movement time period; $\mathrm{RE}$ is defined as $R E(\%)=\frac{\Delta \mathrm{S}_{\text {dug }}-\Delta \mathrm{S}_{\text {model }}}{\Delta \mathrm{S}_{\text {vehicle }}-\Delta \mathrm{S}_{\text {model }}} \times 100 \%$, where $\Delta \mathrm{S}$ 
is the speed changes of zebrafish after light stimulus change.

\subsection{Quality Control Standard}

Successful experiments must meet all the milestones below: (i) zebrafish natural death in untreated and vehicle-treated groups was $\leq 10 \%$; (ii) there was no statistical difference $(\mathrm{p}>0.05)$ in assessed endpoint or signal between untreated and vehicle-treated groups; (iii) intraplate and interplate $\mathrm{CV}$ (coefficient of variation) was $\leq 25 \%$; and (iv) the positive control drug worked ( $\mathrm{p}<0.05$ as compared with model group and mean difference $>1 \mathrm{SD}$ of model group) [16].

\section{Results}

\subsection{Construction of a Zebrafish Model for AD}

To develop a new zebrafish model for rapid anti-AD drug screening and assessment, we first tested the doses for $\mathrm{AlCl}_{3}$ treatment. Three concentrations with $15 \mu \mathrm{M}, 50 \mu \mathrm{M}$ and $150 \mu \mathrm{M} \mathrm{AlCl} 3$ were used to treat zebrafish at $3 \mathrm{dpf}-5 \mathrm{dpf}$. As shown in Figs. 1a and $1 b$, there are no significant changes for AS (average speed) and $\Delta \mathrm{S}$ (speed change) within 15 $\mu \mathrm{M}$ and $50 \mu \mathrm{M} \mathrm{AlCl}_{3}$ groups. Only the $150 \mu \mathrm{M} \mathrm{AlCl}_{3}$ group slows down the movement of zebrafish significantly. The AS and $\Delta \mathrm{S}$, which are $1.54 \pm 0.17$ ( $\mathrm{p}<0.001)$ and $1.70 \pm 0.15(\mathrm{p}<0.01)$ respectively, are $36 \%$ and $37 \%$ lower than the untreated group. $150 \mu \mathrm{M} \mathrm{AlCl}{ }_{3}$ was, therefore, chosen as the optimal exposure concentration.

The $\mathrm{AlCl}_{3}$ exposure duration was optimized after the exposure concentration was fixed. From the results shown in Fig. $1 \mathrm{c}$ and $1 \mathrm{~d}$, the AS and $\Delta \mathrm{S}$ in 4 dpf-5 dpf group are not different from those in the untreated group, whereas a decrease in AS and $\Delta \mathrm{S}$ was observed in $2 \mathrm{dpf}-5 \mathrm{dpf}$ group and the $3 \mathrm{dpf}-5 \mathrm{dpf}$ group. Since the results for both $2 \mathrm{dpf}-5 \mathrm{dpf}$ group and $3 \mathrm{dpf}-5 \mathrm{dpf}$ group were very close, $3 \mathrm{dpf}-5 \mathrm{dpf}$ with a shorter treatment was chosen as the optimal exposure period.

As the first-line drug for AD treatment, DPZ was used as a positive control in the model development. As shown in Fig. 1e and 1f, compared with the untreated group, the $5 \mu \mathrm{M} \mathrm{DPZ} \mathrm{group} \mathrm{only} \mathrm{improved}$ the $\Delta \mathrm{S}$ from $1.35 \pm 0.08$ to $1.79 \pm 0.12(\mathrm{p}<0.05)$ with a response efficacy of $49 \%$, whereas the $10 \mu \mathrm{M} \mathrm{DPZ}$ group showed a potent response efficacy for both the motility (AS, 102\%, p < 0.05) and response $(\Delta \mathrm{S}$, $116 \%, \mathrm{p}<0.01)$. Therefore, $10 \mu \mathrm{M}$ DPZ was chosen as the treatment concentration.

We further assessed the model by dividing the zebrafish into four groups as described in methods 2.3.4 and the behaviour characteristics in each group were examined. As shown in Table 2, the analysis of variance (ANOVA) revealed that there were no statistical differences between the control group and the vehicle group ( $\mathrm{p}>0.05)$, but significant differences were observed between the model group and the vehicle group $(\mathrm{p}<0.05)$, as well as between the model group and the model + DPZ group $(\mathrm{P}<$ $0.05)$. The vehicle group was evaluated in order to check the effect of DMSO in experiments, and indeed there is no significant effect for $0.5 \%$ DMSO, as shown in Fig. 2a. The results were consistent with the report by Senger et al [13]) . Furthermore, the administration of DPZ improved the AS of zebrafish compared to the model + DPZ group. The similar results were also observed in $\Delta \mathrm{S}$ (Fig. $2 \mathrm{~b}$ ). The $\mathrm{AlCl}_{3}$ exposure decreased $\Delta \mathrm{S}$ of the model group to $1.82 \pm$ 0.17 , whereas the model $+\mathrm{DPZ}$ group rescued $\Delta \mathrm{S}$ to $2.44 \pm 0.11$, which was close to the $\Delta \mathrm{S}$ in the vehicle group. The DRR and RE values for DPZ treatment were $90.5 \%$ and $96.9 \%$, respectively.

\subsection{Testing Anti-AD Drugs with a Wide Variety of Targets}

To investigate whether anti-AD drugs could be evaluated in the zebrafish $\mathrm{AD}$ model developed as above, six anti-AD drugs (Rivastigmine, Memantine, ThT, Flurbiprofen, Rosiglitazone and AM-117) either marketed or currently under development with different anti-AD mechanisms were selected and tested in this study. 


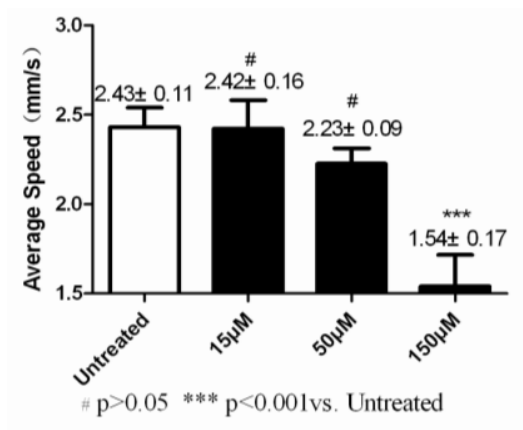

a

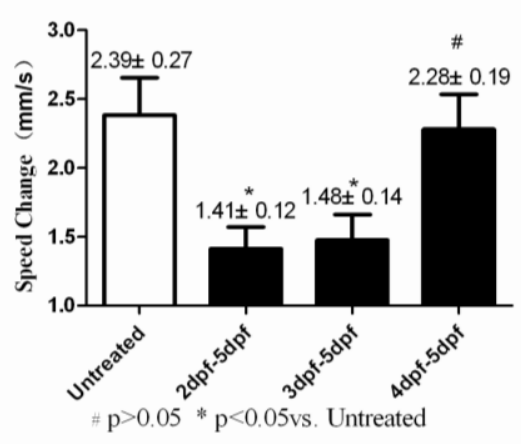

d

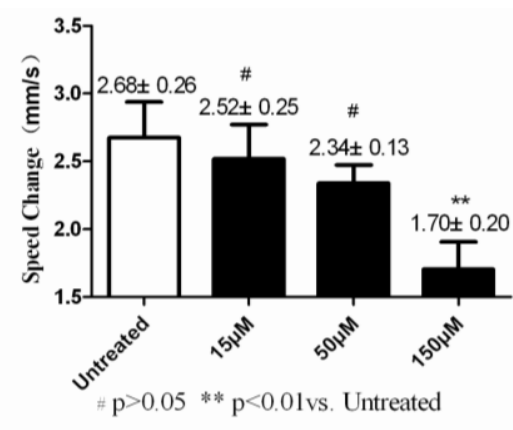

b

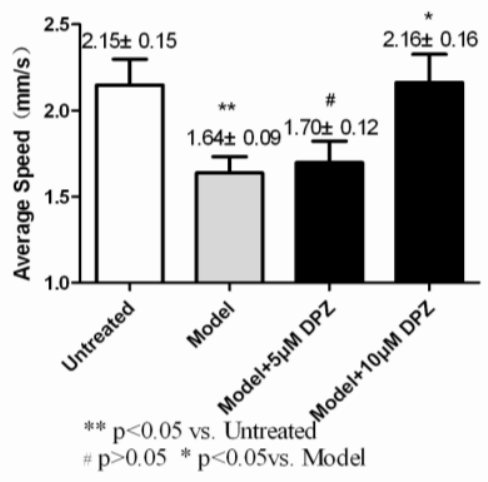

e

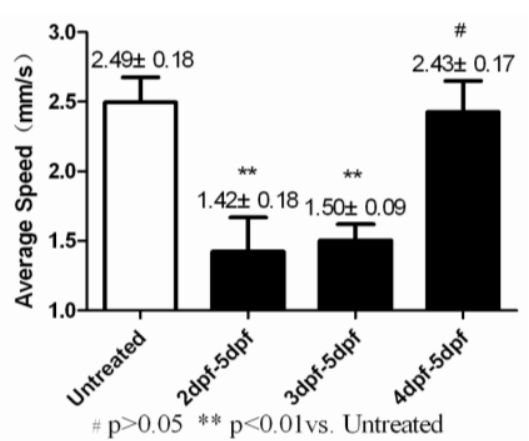

C

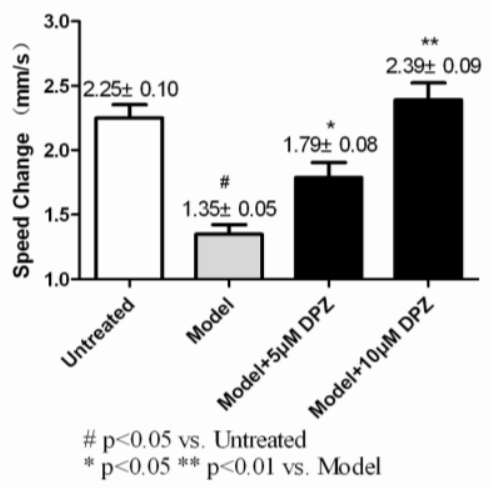

f

Fig. 1 a) and b) Optimization of $\mathrm{AlCl}_{3}$ exposure concentration. The zebrafish from 3 dpf to 5 dpf were treated with $\mathrm{AlCl}_{3}$ at three various concentrations $(15,50$ and $150 \mu \mathrm{M})$ to determine the optimal exposure concentration; c) and d) Optimization of $\mathrm{AlCl}_{3}$ exposure period. $150 \mu \mathrm{M} \mathrm{AlCl}_{3}$ was used to treat zebrafish at various time periods: from $2 \mathrm{dpf}$ to $5 \mathrm{dpf}, 3 \mathrm{dpf}$ to $5 \mathrm{dpf}$ and $4 \mathrm{dpf}$ to $5 \mathrm{dpf}$ respectively; e) and f) Optimization of drug treatment concentration.The zebrafish were co-treated with $150 \mu \mathrm{M} \mathrm{AlCl}{ }_{3}$ and $5 \mu \mathrm{M}$ or $10 \mu \mathrm{M}$ DPZ to determine the concentration of DPZ.

Table 2 The AS and $\Delta S$ values of control, vehicle, model and model + DPZ group $(\mathrm{mm} / \mathrm{s})$.

\begin{tabular}{lll}
\hline Groups & Average Speed (AS) & Speed changes after light stimulus $(\Delta \mathrm{S})$ \\
\hline Control & $2.45 \pm 0.30$ & $2.66 \pm 0.16$ \\
Vehicle & $2.74 \pm 0.32 \#$ & $2.46 \pm 0.18 \#$ \\
Model & $1.91 \pm 0.23^{*}$ & $1.82 \pm 0.17^{*}$ \\
Model+DPZ & $2.48 \pm 0.35^{* *}$ & $2.44 \pm 0.11^{* *}$ \\
\hline
\end{tabular}

$\#$ p $>0.05$ vs. Control; * p < 0.05 vs. Vehicle; $*$ p < 0.05 vs. Model.

\subsubsection{NOAEL of Drugs}

The NOAELs of Rivastigmine, Memantine, ThT, Flurbiprofen, Rosiglitazone and AM-117 were 250, $100,1,10,10,25 \mu \mathrm{M}$, respectively. Based on the NOAELs, we set the high, moderate and low concentrations of each drug (Table 4, the column of concentration) for the efficacy assessment.

\subsubsection{DRR (Dyskinesia Recovery Rate)}

As shown in Table 3, for all six drugs the ASs of the vehicle group were close to those of the control group, while the ASs of the model group were significantly lower than those of the vehicle group. The ASs of the model+ DPZ group were significantly recovered to the level of the vehicle group. These data indicated the reliability and reproducibility of the model. The results also showed that Rivastigmine, Memantine, ThT, Flurbiprofen, Rosiglitazone and AM-117 increased DRR by 53.4-64\%, -9.1-37.3\%, 

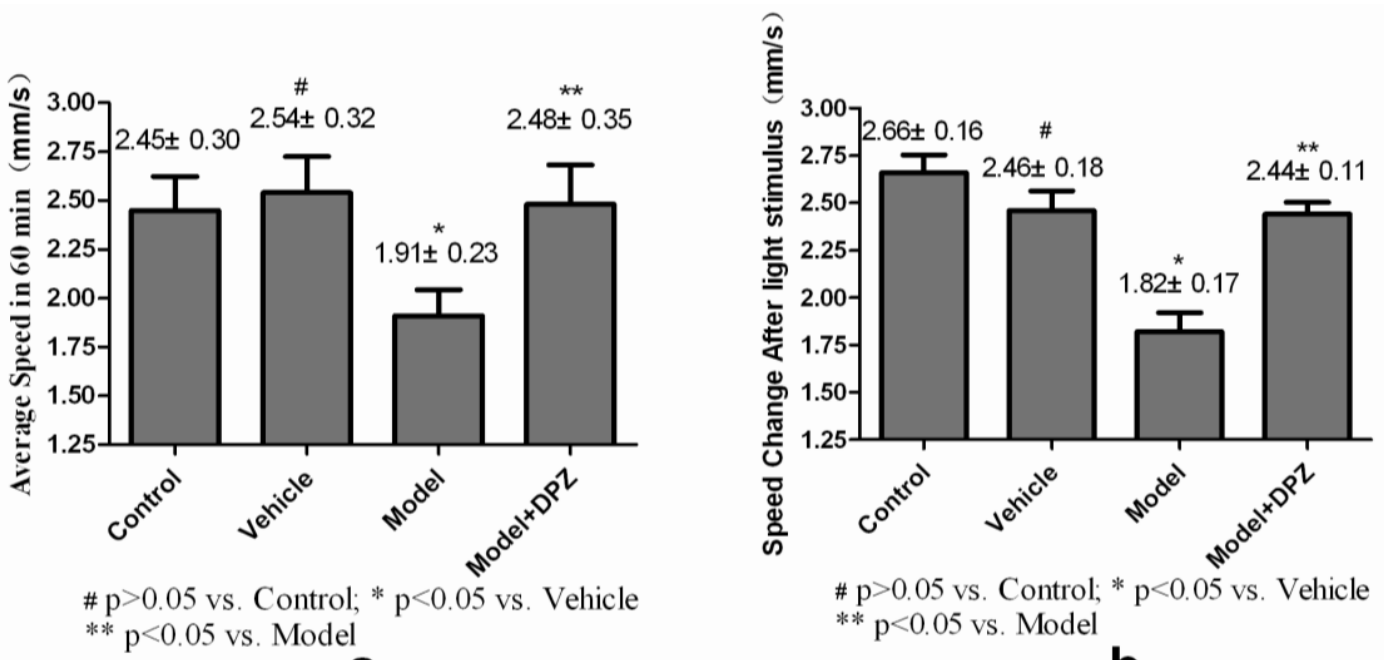

a

\section{b}

Fig. 2 a) The AS (average speed) relative to control/vehicle of zebrafish exposed to $\mathrm{AlCl}_{3}$ only, or treating with $\mathrm{DPZ}$. b) Speed change after light stimulus $(\Delta S)$ relative to control/vehicle of zebrafish exposed to $\mathrm{AlCl}_{3}$ only, or treating with DPZ.

Table 3 The average speed (AS) of six drugs $(\mathrm{mm} / \mathrm{s})$.

\begin{tabular}{|c|c|c|c|c|c|c|c|c|}
\hline Groups & Control & Vehicle & Model & $\begin{array}{l}\text { Control + } \\
\text { DrugC }_{\text {high }} \\
\end{array}$ & $\begin{array}{l}\text { Model + } \\
\text { DPZ }\end{array}$ & $\begin{array}{l}\text { Model + } \\
\text { DrugC }_{\text {low }} \\
\end{array}$ & $\begin{array}{l}\text { Model + } \\
\text { DrugC }_{\text {moderate }}\end{array}$ & $\begin{array}{l}\text { Model + } \\
\text { DrugC }_{\text {high }} \\
\end{array}$ \\
\hline Rivastigmine & $2.85 \pm 0.20$ & $2.74 \pm 0.17 \#$ & $1.48 \pm 0.17 \# \#$ & $2.70 \pm 0.20 \#$ & $2.25 \pm 0.17 \# \# \#$ & $2.15 \pm 0.16^{* *}$ & $2.28 \pm 0.18 * * *$ & $2.22 \pm 0.18^{* *}$ \\
\hline Memantine & $2.82 \pm 0.16$ & $2.45 \pm 0.19 \#$ & $1.69 \pm 0.18 \# \#$ & $1.07 \pm 0.12 \# \# \# \#$ & $2.37 \pm 0.18 \# \# \#$ & $1.97 \pm 0.18 * * * *$ & $1.62 \pm 0.19 * * * *$ & $1.76 \pm 0.24 * * * *$ \\
\hline ThT & $2.16 \pm 0.16$ & $2.32 \pm 0.16 \#$ & $1.89 \pm 0.18 \# \#$ & $2.30 \pm 0.17 \#$ & $2.45 \pm 0.17 \# \# \#$ & $2.69 \pm 0.20 * * *$ & $2.63 \pm 0.20 * * *$ & $2.76 \pm 0.17 * * *$ \\
\hline Flurbiprofen & $2.20 \pm 0.13$ & $2.54 \pm 0.16 \#$ & $1.95 \pm 0.17 \# \#$ & $2.27 \pm 0.23 \#$ & $2.50 \pm 0.16 \# \# \#$ & $2.27 \pm 0.16^{* * * *}$ & $2.52 \pm 0.20 *$ & - \\
\hline Rosiglitazone & $2.87 \pm 0.20$ & $2.60 \pm 0.18 \#$ & $1.92 \pm 0.19 \# \#$ & $2.08 \pm 0.17 \# \# \# \#$ & $2.37 \pm 0.22 \# \# \#$ & $1.99 \pm 0.18 * * * *$ & $2.07 \pm 0.17 * * * *$ & $1.66 \pm 0.18 * * * *$ \\
\hline AM-117 & $2.54 \pm 0.16$ & $2.24 \pm 0.16 \#$ & $1.80 \pm 0.16 \# \#$ & $2.51 \pm 0.15 \#$ & $2.30 \pm 0.14 \# \# \#$ & $2.11 \pm 0.14 * * * *$ & $2.24 \pm 0.14^{*}$ & $2.33 \pm 0.17 * *$ \\
\hline
\end{tabular}
\# p > 0.05 vs. Control; \#\# p < 0.05 vs. Vehicle; \#\#\# p < 0.05 vs. Model; \#\#\#\# p < 0.05 vs. Control; * p < 0.05 vs. Model; ** p < 0.005 vs. Model; $* * * \mathrm{p}<0.001$ vs. Model; $* * * * \mathrm{p}>0.05$ vs. Model; All the values presented are the average speed of the drug treated fish.

Table 4 The DRR values of six drugs at low, moderate and high concentrations.

\begin{tabular}{llllllll}
\hline Drug & $\begin{array}{l}\text { Concentration } \\
(\mu \mathrm{M})\end{array}$ & DRR\% & $\mathrm{p}$ & Drug & $\begin{array}{l}\text { Concentration } \\
(\mu \mathrm{M})\end{array}$ & DRR\% & $\mathrm{p}$ \\
\hline \multirow{3}{*}{ Rivastigmine } & 10 & 53.4 & 0.00298 & & 1 & 54.5 & 0.17434 \\
& 50 & 64.0 & 0.00012 & Flurbiprofen & 2.5 & 96 & 0.04129 \\
& 250 & 58.6 & 0.00310 & & 10 & - & - \\
\hline \multirow{3}{*}{ Memantine } & 10 & 37.3 & 0.15676 & & 1 & 9.6 & 0.7307 \\
& 50 & -9.1 & 0.73492 & Rosiglitazone & 2.5 & 21.4 & 0.50376 \\
& 100 & 9.2 & 0.73728 & & 10 & -37.8 & 0.12928 \\
\hline \multirow{2}{*}{ THT } & 0.1 & 183.3 & 0.00023 & & 1 & 70.8 & 0.09505 \\
& 0.25 & 169.4 & 0.00342 & AM-117 & 5 & 99.3 & 0.03251 \\
& 1 & 200 & 0.00044 & & 25 & 121 & 0.00329 \\
\hline
\end{tabular}

All the values presented are calculated by the average speed of the drug treated fish.

$169.4-200 \%, 54.5-96 \%,-37.8-9.6 \%$ and $70.9-121 \%$, respectively (Fig. 3). Statistically significant positive effect on DRR (Table 4) was observed at a low concentration of Rivastigmine $(\mathrm{p}<0.005)$ and ThT (p $<0.001)$, at a moderate concentration of Rivastigmine $(\mathrm{p}<0.001)$, ThT $(\mathrm{p}<0.005)$, Flurbiprofen $(\mathrm{p}<0.05)$ and AM-117 ( $\mathrm{p}<0.05)$, and at a high concentration of Rivastigmine $(\mathrm{p}<0.005)$, ThT $(\mathrm{p}<0.001)$ and AM-117 ( $\mathrm{p}<0.005$ ). Memantine and Rosiglitazone had no significant effect on DRR ( $p>0.05$; Table 4). 


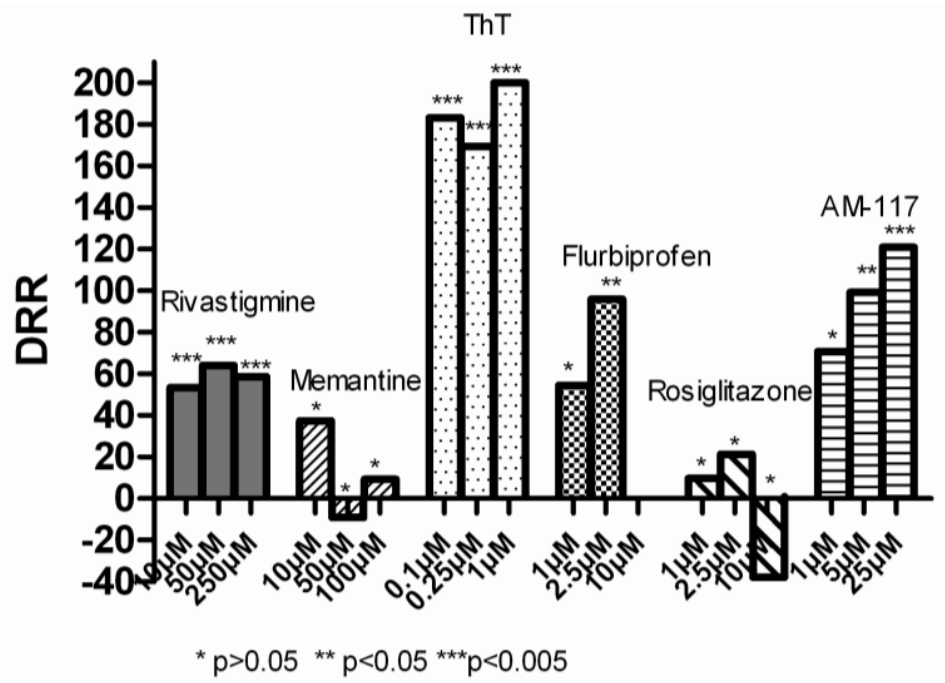

Fig. 3 The DRR values of six drugs (Rivastigmine, Memantine, ThT, Flurbiprofen, Rosiglitazone and AM-117).

Table 5 Speed changes after light stimulus alteration of six drugs $(\mathrm{mm} / \mathrm{s})$.

\begin{tabular}{|c|c|c|c|c|c|c|c|c|}
\hline Groups & Control & Vehicle & Model & $\begin{array}{l}\text { Control + } \\
\text { DrugC }_{\text {high }}\end{array}$ & $\begin{array}{l}\text { Model + } \\
\text { DPZ }\end{array}$ & $\begin{array}{l}\text { Model + } \\
\text { DrugC }_{\text {low }}\end{array}$ & $\begin{array}{l}\text { Model + } \\
\text { DrugC } \\
\text { moderate }\end{array}$ & $\begin{array}{l}\text { Model + } \\
\text { DrugC }_{\text {high }}\end{array}$ \\
\hline Rivastigmine & $2.42 \pm 0.23$ & $2.48 \pm 0.13 \#$ & $1.50 \pm 0.15 \# \#$ & $2.49 \pm 0.21 \#$ & $2.19 \pm 0.14 \# \# \#$ & $2.73 \pm 0.10 * * *$ & $2.35 \pm 0.12 * * *$ & $3.21 \pm 0.08^{* * *}$ \\
\hline Memantine & $2.08 \pm 0.14$ & $2.33 \pm 0.17 \#$ & $1.39 \pm 0.11 \# \#$ & $2.29 \pm 0.12 \#$ & $2.45 \pm 0.13 \# \# \#$ & $1.65 \pm 0.10 * * * *$ & $1.85 \pm 0.09 * *$ & $2.01 \pm 0.11 *$ \\
\hline ThT & $2.24 \pm 0.13$ & $2.29 \pm 0.16 \#$ & $1.62 \pm 0.17 \# \#$ & $2.10 \pm 0.09 \#$ & $2.21 \pm 0.14 \# \# \#$ & $2.47 \pm 0.13^{* * *}$ & $3.20 \pm 0.10^{* * *}$ & $3.07 \pm 0.09^{* * *}$ \\
\hline Flurbiprofen & $2.40 \pm 0.09$ & $2.28 \pm 0.11 \#$ & $1.91 \pm 0.12 \# \#$ & $1.92 \pm 0.08 \# \# \# \#$ & $2.88 \pm 0.10 \# \# \#$ & $2.35 \pm 0.09 * *$ & $3.11 \pm 0.67 * * *$ & - \\
\hline Rosiglitazone & $2.05 \pm 0.11$ & $2.40 \pm 0.16 \#$ & $1.58 \pm 0.10 \# \#$ & $2.61 \pm 0.10 \#$ & $2.17 \pm 0.09 \# \# \#$ & $2.16 \pm 0.11^{* * *}$ & $2.74 \pm 0.12 * * *$ & $1.80 \pm 0.10^{* * * *}$ \\
\hline AM-117 & $2.12 \pm 0.16$ & $2.10 \pm 0.19 \#$ & $1.60 \pm 0.12 \# \#$ & $1.39 \pm 0.13 \# \# \# \#$ & $2.70 \pm 0.12 \# \# \#$ & $2.16 \pm 0.12^{* * *}$ & $2.40 \pm 0.15^{* * *}$ & $1.95 \pm 0.08 *$ \\
\hline
\end{tabular}

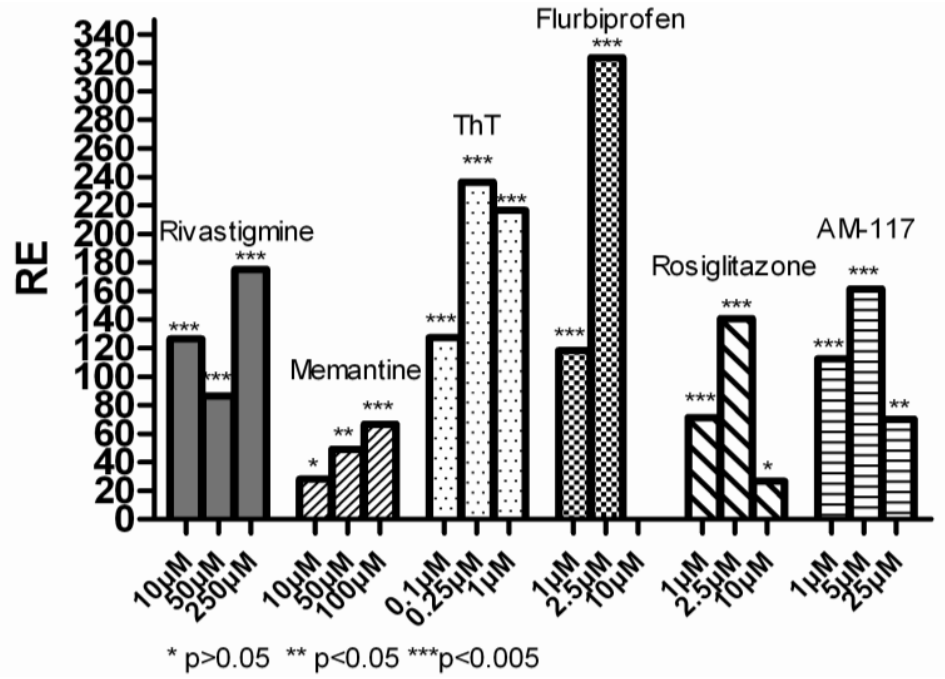

Fig. 4 The RE values of six drugs (Rivastigmine, Memantine, ThT, Flurbiprofen, Rosiglitazone and AM-117).

\subsubsection{RE (Response Efficiency)}

Another parameter described in the zebrafish model was RE, which reflected the changes of the zebrafish swimming speed after light stimulus change from light to dark or from dark to light. As shown in Table 5, the $\Delta \mathrm{S}$ s in control group, vehicle group, model group and model + DPZ group further supported the reliability and reproducibility of the model and the RE values for 
Table 6 The RE values of six drugs at low, moderate and high concentrations.

\begin{tabular}{llllllll}
\hline Drug & $\begin{array}{l}\text { Concentration } \\
(\mu \mathrm{M})\end{array}$ & $\mathrm{RE} \%$ & $\mathrm{p}$ & Drug & $\begin{array}{l}\text { Concentration } \\
(\mu \mathrm{M})\end{array}$ & $\mathrm{RE} \%$ & $\mathrm{p}$ \\
\hline \multirow{3}{*}{ Rivastigmine } & 10 & 126.3 & 0 & & 1 & 118.3 & 0.00492 \\
& 50 & 86.6 & 0.00004 & Flurbiprofen & 2.5 & 323.7 & 0 \\
\hline \multirow{3}{*}{ Memantine } & 250 & 175.1 & 0 & & 10 & - & - \\
& 10 & 28.2 & 0.1028 & & 1 & 71.2 & 0.00026 \\
& 100 & 49.1 & 0.00218 & Rosiglitazone & 2.5 & 140.8 & 0 \\
\multirow{2}{*}{ THT } & 0.1 & 66.6 & 0.00024 & & 10 & 26.6 & 0.12563 \\
& 0.25 & 127.2 & 0.0002 & & 1 & 112.4 & 0.00228 \\
& 1 & 236.5 & 0 & AM-117 & 5 & 161.4 & 0.00013 \\
\end{tabular}

All the values presented are calculated by the average speed of the drug treated fish.

Rivastigmine, Memantine, ThT, Flurbiprofen, Rosiglitazone and AM-117 were 86.6-175.1\%, $28.2-66.6 \%, \quad 127.2-236.5 \%, \quad 118.3-323.7 \%$, 26.6-140.8\% and 70.2-161.4\%, respectively (Fig. 4). Statistically significant positive effect on RE (Table 6) was observed at low, moderate and high concentrations for Rivastigmine $(\mathrm{p}<0.001)$ and ThT ( $p<0.001)$, at moderate and high concentrations for Memantine ( $\mathrm{p}<0.005)$, and at low and moderate concentrations for Flurbiprofen $(\mathrm{p}<0.005)$, Rosiglitazone ( $\mathrm{p}<0.001)$ and AM-117 ( $<0.005)$.

\section{Discussion}

The primary goal of this work was to develop an in vivo zebrafish model which could be used for screening anti-AD drugs. Different from the model reported by Senger et al., [13] who used adult zebrafish, in this study we employed larval zebrafish for the model development. After determining the optimal doses and duration for $\mathrm{AlCl}_{3}$ treatment, the zebrafish AD model was successfully established, and the data shown in Table 2 indicated the reliability and reproducibility of the model. The model as finally validated by six commercial AD drugs. Except Memantine and Rosiglitazone, our model significantly responded the rest four drug treatment in the measurement of both DRR and RE. For the limitations of the study, the zebrafish model developed and validated in this study could be a rapid and high throughput screening method in drug discovery to find the hits, which could further be confirmed by the classical AD model and transgenic animal model.

Rivastigmine is one of the five acetylcholinesterase inhibitors approved for AD treatment [17], among which DPZ and Rivastigmine are the world's best-selling anti-AD drugs. It showed the highest NOAEL and moderate effect on speed recovery of zebrafish $(\mathrm{DDR}=53.4 \%-64.0 \%$ with $\mathrm{p}<0.005)$ among the six drugs. In contrast, Rivastigmine showed high RE values (86.6\%-175.1\%) with $\mathrm{p}<$ 0.0001 . Since DPZ is also an acetylcholinesterase inhibitor, this model might be suitable for the study of acetylcholinesterase inhibitors, especially in the context of RE.

Besides acetylcholinesterase inhibitors, another important anti-AD drug approved for marketing is Memantine, which is an N-methyl-D-aspartic acid receptor antagonist [17]. Since the excess of glutaminergic stimulation results in an over-activation of the N-methyl-D-aspartic acid receptor, which leads to calcium overflow into the neurons and thus promoting cell death, Memantine can block the $\mathrm{N}$-methyl-D-aspartic acid receptor, decrease cell death and alleviate symptoms of AD. As shown in Table 3, after Memantine treatment with low concentration (10 $\mu \mathrm{M})$, the average speed of zebrafish was partially recovered, while no significant change was observed in moderate $(50 \mu \mathrm{M})$ and high concentration $(100 \mu \mathrm{M})$ groups. Furthermore, the observation that the AS of 
the Control + DrugC $_{\text {high }}$ group is significantly lower than the vehicle group suggests the neurotoxicity of Memantine at high concentration $(100 \mu \mathrm{M})$. This result indicates that DRR might not be the suitable parameter in this model for Memantine, however, RE can be used as a parameter in the measurement of RE could be used for the screening of anti-AD drugs targeting the N-methyl-D-aspartic acid receptor (Table 6).

$A \beta$ (Amyloid- $\beta$ ), formed by the continuously proteolytic processing of $\beta$-amyloid precursor protein by $\beta$ - and $\gamma$-secretase $[18,19]$, plays a central role in the pathogenesis of AD. The degradation of $A \beta$ in the brain can be increased by the activation of PPAR $\gamma$ receptor via increasing the level and activity of the IDE (insulin degradation enzyme) [20, 21]. Therefore, three drugs (ThT, Flurbiprofen and Rosiglitazone) targeting at aggregation, generation and degradation of $A \beta$ respectively were selected for the model validation. ThT, an inhibitor of $\mathrm{A} \beta$ aggregation, is a tool medicine for AD. Flurbiprofen and Rosiglitazone, approved as a nonsteroidal anti-inflammatory drug and a hypoglycemic drug, are in the clinical trials for $\mathrm{AD}$ as a $\gamma$-secretase inhibitor and a PPAR $\gamma$ agonist. As shown in Table 4 and Table 6, both ThT and Flurbiprofen had effects on DRR and RE, while Rosiglitazone only affected RE. This could be explained by the mechanism of Rosiglitazone. Rosiglitazone is targeting at degradation of $A \beta$, which is after aggregation and generation phase. Therefore, it might take longer for Rosiglitazone to affect DRR. Notably, all zebrafish were dead when treated with $10 \mu \mathrm{M}$ of Flurbiprofen. These results indicate that high concentrations of $\gamma$-secretase inhibitor and aluminum ions may have toxic effects on zebrafish. Another reason may due to the side-effect of $\gamma$-secretase inhibitors, in which the treatment affects the Notch signal pathway related to the growth of neural cells [22]. This observation is perfectly in line with the results in which knockdown of $\gamma$-secretase is lethal in mice model [23]. Therefore, $\gamma$-secretase inhibitors with suitable concentration could be used in this model as anti-AD drugs screening.

It was reported the level of metal ions in $\mathrm{AD}$ patients is 3-7 folds higher than that of healthy individuals [24], which suggest that the dyshomeostasis of biometals ( $\mathrm{Fe}, \mathrm{Cu}, \mathrm{Zn}$ ) in the brain may contribute to $\mathrm{AD}$ pathology. Additionally, simultaneous inhibition of acetylcholinesterase and decrease of metal ions may form a synergistic effect on the treatment of $\mathrm{AD}[25,26]$, as both drugs decelerate the $A \beta$ aggregation via different mechanisms. Therefore, AM-117, an acetylcholinesterase inhibitor and a pro-metal chelator, was designed as a MTDL (multitarget-directed ligand) in our laboratory (none publication data). It's not surprised that our data showed the DRR measurement was increased in a dose-dependent manner upon AM-117 treatment. In addition, the effect of AM-117 was similar to that of DPZ although targeting two different targets. Upon penetrating into the brain, AM-117 first inhibits acetylcholinesterase, and in return AM-117 is then hydrolyzed to AM-117a which acts as a metal chelator. Since AS was measured three days after drug treatment, most of AM-117 might not be hydrolyzed, thus could not serve as a metal chelator.

\section{Conclusion}

In the present study, we developed a motility- and response ability- based in vivo screening animal model using larval zebrafish in order to cut the experiment cost and duration, and increase the experimental reproducibility. Six commercial drugs with various inhibitory mechanisms were tested in this model. The $\mathrm{RE}$ as a biomarker developed for this model could be used for screening the compounds targeting $\mathrm{N}$-methyl-D-aspartic acid receptor, $\mathrm{A} \beta$, acetylcholinesterase, $\gamma$-secretase and PPAR- $\gamma$. Our work suggested that the novel zebrafish AD model may be a useful system for high throughput primary screening of novel anti-AD compounds. 


\section{Acknowledgments}

The authors thank the National Natural Science Foundation of China (81302646), Natural Science Foundation of Zhejiang Province (LQ13H300002), Science Technology Department of Zhejiang Province (2015F50015) and Health and Family Planning commission of Zhejiang Province (XKQ-010-001 and 2013KYB070) for financial support.

\section{References}

[1] Ghosh, A. K., Kumaragurubaran, N., and Tang, J. 2005. "Recent Developments of Structure Based $\beta$-secretase Inhibitors for Alzheimer's Disease." Current Topics in Medicinal Chemistry, 5: 1609-22.

[2] Guo, T., and Hobbs, D. W. 2006. "Development of BACE1 Inhibitors for Alzheimers Disease." Current Medicinal Chemistry, 13: 1811-29.

[3] Anne, R.,Yan, L.,Michel, N., and Bernard, M. 2015. "Regulation of Copper and Iron Homeostasis by Metal Chelators: A Possible Chemotherapy for Alzheimer's Disease." Accounts of Chemical Research 48: 1332-9.

[4] Michele, T., Marco, C., Bruno, T., Federica, N., Caterina, C., Giovanna, L., Leonardo, P., Angelo, D., S., Nunzio, D., Anna, S., Vito, B., Angelo, C., and Fabio, S. 2015. "Multitarget Therapeutic Leads for Alzheimer's Disease: Quinolizidinyl Derivatives of Bi- and Tricyclic Systems as Dual Inhibitors of Cholinesterases and b-Amyloid (Ab) Aggregation." Chem Med Chem 10: 1040-53.

[5] Huang, W., Wei, W., and Shen, Z. 2014 "The Drug-like Chelating Agents: The Potential Lead for Alzheimer's Disease." RSC Advance 94: 52088-99.

[6] Newman, M., Musgrave, F., and Lardelli, M. 2007. "Alzheimer Disease: Amyloidogenesis, the Presenilins and Animal Models." Biochimica et Biophysica Acta (BBA)-Molecular Basis of Disease 1772: 285-97.

[7] Newman, M., Verdile, G., Martins, R. N., and Lardelli, M. 2011. "Zebrafish as a Tool in Alzheimer's Disease Research." Biochimica et Biophysica Acta (BBA)-Molecular Basis of Disease 1812: 346-52.

[8] Paquet, D., Bhat, R., Sydow, A., Mandelkow, E. M., Berg, S., Hellberg, S., Fälting, J., Distel, M., Köster, R. W., and Schmid, B. 2009. "A Zebrafish Model of Tauopathy Allows in Vivo Imaging of Neuronal Cell Death and Drug Evaluation." The Journal of Clinical Investigation 119: 1382.

[9] Zhong, H., Zou, H., Semenov, M. V., Moshinsky, D., He, X., Huang, H., Li, S., Quan, J., Yang, Z., and Lin, S. 2009. "Characterization and Development of Novel Small-molecules Inhibiting GSK3 and Activating Wnt
Signaling." Mol. BioSyst., 5: 1356-60.

[10] Zou, H., Zhou, L., Li, Y., Cui, Y., Zhong, H., Pan, Z., Yang, Z., and Quan, J. 2009. "Benzo [e] Isoindole-1, 3-diones as Potential Inhibitors of Glycogen Synthase Kinase-3 (GSK-3). Synthesis, Kinase Inhibitory Activity, Zebrafish Phenotype, and Modeling of Binding Mode." Journal of Medicinal Chemistry 53: 994-1003.

[11] He, X., Zhong, Z. M., and Che, Y. 2012. "Locomotor Activity and Learning and Memory Abilities in Alzheimer's Disease Induced by Aluminum in an Acid Environment in Zebrafish." Zoological Research 33: 231-6.

[12] Fang, M., and Zhang, H. 2012. "Effects of Extract from Semen Persicae on SOD, GSH-Px Activity and MDA Contents of Brain Tissue in Mice Dementia Model." Chinese Journal of Experimental Traditional Medical Formulae 16: 236-8.

[13] Senger, M. R., Seibt, K. J., Ghisleni, G. C., Dias, R. D., Bogo, M. R., and Bonan, C. D. 2011. "Aluminum Exposure Alters Behavioral Parameters and Increases Acetylcholinesterase Activity in Zebrafish (Danio Rerio) Brain." Cell Biology and Toxicology 27: 199-205.

[14] Jeong, J. Y., Kwon, H. B., Ahn, J. C., Kang, D., Kwon, S. H., Park, J. A., and Kim, K. W. 2008. "Functional and Developmental Analysis of the Blood-brain Barrier in Zebrafish." Brain Research Bulletin 75: 619-28.

[15] McGrath, P. 2012. Zebrafish: Methods for Assessing Drug Safety and Toxiety. John Wiley and Sons, Inc. (Chapter 17).

[16] Zhou, J., Guo, S. Y., Zhang, Y., and Li, C. Q. 2014. "Human Prokinetic Drugs Promote Gastrointestinal Motility in Zebrafish." Neurogastroenterology and Motility 26: 589-95.

[17] HUANG, S. F., HUANG, W. H., and HU, Y. 2011. "Development of Multiple-target Anti-Alzheimer' s Agents." Chinese Journal of Medicinal Chemistry 21: 433-41.

[18] John, V., Beck, J. P., Bienkowski, M. J., Sinha, S., and Heinrikson, R. L. 2003. "Human $\beta$-secretase (BACE) and BACE Inhibitors." Journal of Medicinal Chemistry 46: 4625-30.

[19] Komilova, A. Y., and Wolfe, M. S. 2003. "Secretase Inhibitors for Alzheimer's Disease." Annual Reports in Medicinal Chemistry 38: 41.

[20] Landreth, G. 2007. "Therapeutic Use of Agonists of the Nuclear Receptor PPAR in Alzheimers Disease." Current Alzheimer Research 4: 159-64.

[21] Landreth, G., Jiang, Q., Mandrekar, S., and Heneka, M. 2008. "PPAR $\gamma$ Agonists as Therapeutics for the Treatment of Alzheimer's Disease." Neurotherapeutics 5: 481-9.

[22] Huang, W., Yu, H., Sheng, R., Li, J., and Hu, Y. 2008. 
"Identification of Pharmacophore Model, Synthesis and Biological Evaluation of N-phenyl-1-arylamide and N-phenylbenzenesulfonamide Derivatives as BACE 1 Inhibitors." Bioorganic and Medicinal Chemistry 16: 10190-7.

[23] Cuello, A., and Bell, K. 2005. "Strategies to Diminish the Ab Load in Alzheimer's Disease." Current Medicinal Chemistry-Central Nervous System Agents 5: 15-28.

[24] Zatta, P., Drago, D., Bolognin, S., and Sensi, S. L. 2009. "Alzheimer's Disease, Metal Ions and Metal Homeostatic Therapy." Trends in Pharmacological Sciences, 30, 346-355.
[25] Huang, W., Lv, D., Yu, H., Sheng, R., Kim, S. C., Wu, P., Luo, K., Li, J., and Hu, Y. 2010. "Dual-target-directed 1, 3-diphenylurea Derivatives: BACE 1 Inhibitor and Metal Chelator Against Alzheimer's Disease." Bioorganic and Medicinal Chemistry 18: 5610-5.

[26] Huang, W., Tang, L., Shi, Y., Huang, S., Xu, L., Sheng, R., Wu, P., Li, J., Zhou, N., and Hu, Y. 2011. "Searching for the Multi-Target-Directed Ligands Against Alzheimer's Disease: Discovery of Quinoxaline-based Hybrid Compounds with $\mathrm{AChE}, \mathrm{H}_{3} \mathrm{R}$ and BACE 1 Inhibitory Activities." Bioorganic and Medicinal Chemistry 19: 7158-67. 
Graph Abstract
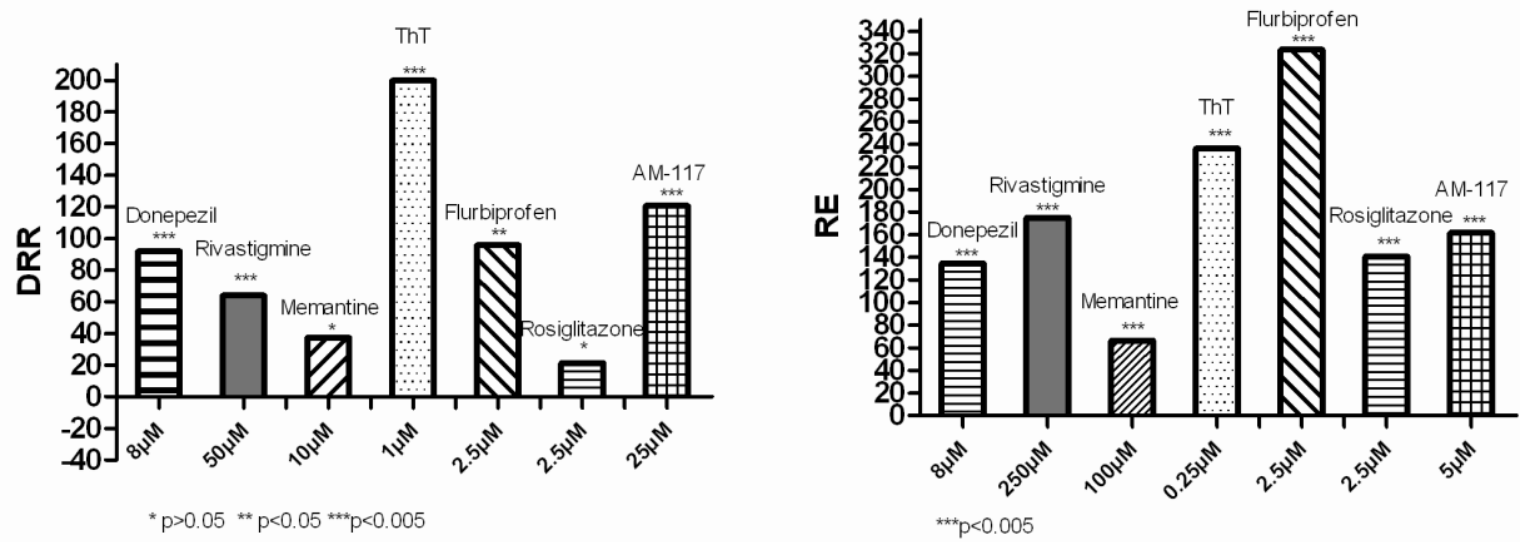

A new animal model using 3dpf to 5dpf larval zebrafish with DPZ (donepezil) as positive control was developed for the biological evaluation of anti-AD compounds. Furthermore, six anti-AD drugs marketed, or in clinical trials with a variety of mechanisms were tested to validate the newly developed zebrafish AD model.

Chemical compounds:

Donepezil (PubChem CID: 3152); Rivastigmine (PubChem CID: 77990); Memantine (PubChem CID: 181458); Thioflavine T (PubChem CID: 24900146); Flurbiprofen (PubChem CID: 87570142); Rosiglitazone (PubChem CID: 77999) 